\title{
An Improved Evans Blue Staining Method for Consistent, Accurate Assessment of Plasmodiophora brassicae Resting Spore Viability
}

\author{
M. W. Harding, ${ }^{1, \dagger}{ }^{\dagger}$ T. B. Hill, ${ }^{1}$ Y. Yang, ${ }^{2}$ G. C. Daniels, ${ }^{1}$ S. F. Hwang, ${ }^{2}$ S. E. Strelkov, ${ }^{3}$ R. J. Howard, ${ }^{4}$ and J. Feng $^{2}$ \\ ${ }^{1}$ Crop Diversification Centre South, Alberta Agriculture and Forestry, Brooks, AB T1R 1E6, Canada \\ ${ }^{2}$ Crop Diversification Centre North, Alberta Agriculture and Forestry, Edmonton, AB T5Y 6H3, Canada \\ ${ }^{3}$ Department of Agricultural, Food and Nutritional Science, University of Alberta, Edmonton, AB T6G 2P5, Canada \\ ${ }^{4}$ RJH Ag Research Solutions Ltd., Brooks, AB T1R 1C3, Canada
}

\begin{abstract}
Clubroot caused by Plasmodiophora brassicae is an important disease of brassica crops. The use of vital stains to determine the viability of $P$. brassicae resting spores can provide useful information regarding spore longevity, inoculum potential, or the efficacy of antimicrobial treatments. Evans blue is one example of a vital stain that has been reported to differentially stain viable and nonviable resting spores. Some previously published protocols using Evans blue to stain P. brassicae resting spores have not provided accurate or consistent results. In this study, we modified the Evans blue method by increasing the staining time to $8 \mathrm{~h}$ or more and evaluated $P$. brassicae resting spores after heat treatment at various

which the numbers of stained spores did not change significantly $\left(R^{2}=96.88 ; P \leq 0.001\right)$. The accuracy of the modified method to discriminate viable and nonviable spores was evaluated in repeated experiments and by comparing the staining data with those derived from inoculation assays and propidium monoazide quantitative PCR (qPCR). The results demonstrated that the modified Evans blue staining method improved the accuracy and consistency of measurement of $P$. brassicae resting spore viability. Additionally, it was equivalent to the qPCR method for differentiating viable and nonviable spores $\left(R^{2}=99.84 ; P \leq 0.001\right)$ and confirmed in canola infection bioassays.
\end{abstract} combinations of temperature and time. Extending staining times significantly increased the numbers of stained resting spores up to $7 \mathrm{~h}$, after
Keywords: azo dye, T-1824, quantitative real-time PCR
The impact of clubroot (Plasmodiophora brassicae Woronin) on brassica crops in Canada began to increase dramatically after the first report of the disease on canola (Brassica napus L) in 2003 by Tewari et al. (2005). The report of clubroot on canola came from the Province of Alberta, which before 2003, had only rarely reported clubroot symptoms on vegetables in backyard gardens and market gardens (Howard et al. 2010). Its transition into canola fields was an important development because of the potential for rapid buildup of resting spores in large fields growing susceptible canola cultivars, the significant economic impact because of yield loss, and the large proportion of agricultural fields ( $\sim 7$ million acres or $\sim 30 \%)$ used for canola production across the province. Additionally, many Alberta fields are very conducive to clubroot disease initiation and symptom development because of their high-moisture and low-pH soil characteristics. Research on methods for avoidance, containment, and management of clubroot have revealed a great deal about this disease in large-scale field crop production systems on the Canadian Prairies, but despite these efforts, the pathogen continues to spread to new fields and overcome the genetic resistances deployed in modern canola cultivars (Gossen et al. 2015; Hwang et al. 2014; Strelkov et al. 2018).

Two key factors make $P$. brassicae challenging to manage. First, populations maintain high pathotypic diversity, which can rapidly shift to become virulent on previously resistant hosts (Strelkov et al. 2014, 2015, 2018). Second, it has the ability to form millions of dormant resting spores in a single host root, many of which are capable of surviving many years in soils. These spores can survive a

${ }^{\dagger}$ Corresponding author: M. W. Harding; michael.harding@gov.ab.ca

Funding: Sponsorship of this work from Growing Forward 2 (Agriculture and Agri-Food Canada and the Canola Council of Canada) and Alberta Agriculture and Forestry is gratefully acknowledged.

The author(s) declare no conflict of interest.

Accepted for publication 7 April 2019.

() 2019 The American Phytopathological Society broad range of conditions that many microbial propagules cannot. For example, heat treatment via composting or soil solarization can inactivate many fungal and bacterial pathogens but is not fully effective against clubroot resting spores unless stringent temperature, moisture, and exposure times are met (Fayolle et al. 2006; Myers et al. 1983; Wichuk et al. 2011).

One of the challenges for researchers working with $P$. brassicae is the pathogen's biotrophic lifestyle, which makes it impossible to obtain actively growing cultures of the pathogen or study it in vitro or in the absence of living host roots or host cells (Kageyama and Asano 2009). The pathogen survives in soil as resting spores that remain metabolically inactive while awaiting cues from plant roots and/or the environment to exit dormancy and attempt to initiate infection. Resting spores, although dormant, represent a stage of the $P$. brassicae life cycle that is more amenable to laboratory analyses than others, such as the short-lived zoospores that are released from germinated resting spores or plasmodia that only develop in planta. Evaluating resting spore viability is important for many reasons, including predicting disease potential; measuring efficacies of control products; and improving our understanding of factors affecting clubroot survival, spread, and risk management.

A rapid, accurate method to enumerate viable resting spores using quantitative PCR (qPCR) was reported by Al-Daoud et al. (2017), where DNA from nonviable spores was excluded from detection by pretreating the spores with propidium monoazide (PMA). This chemical penetrates nonviable spores but does not penetrate viable spores, and it binds DNA, inhibiting amplification. Using PMA qPCR, Al-Daoud et al. (2017) were able to provide reliable estimates of viable resting spore concentrations. Before the PMA qPCR method, viable resting spore counts were obtained using a vital staining method that attempted to quantify or estimate spore viability. Vital stains are chemical dyes that are taken up differentially by viable (living) versus nonviable (dead) cells. Vital stains can be very accurate, because the assessment is done directly by viewing the staining or lack of staining of actual spores rather than indirectly by measuring molecular amplification. Some of these stains have been used to evaluate the viability of $P$. brassicae resting spores (Lee and Hsieh 1992). Evans blue is an example of a vital stain that will only be taken 
up by nonviable $P$. brassicae resting spores (Lahlali et al. 2011; Lahlali and Peng 2014; Rennie et al. 2011; Takahashi and Yamaguchi 1987; Tanaka et al. 1999). Although some of these authors have reported success with Evans blue staining, efforts to utilize Evans blue staining to evaluate $P$. brassicae resting spore mortality have found serious issues with the accuracy and consistency of results obtained using the published staining method (Al-Daoud et al. 2017) (Howard and Harding, unpublished data). In this study, we describe a modification to the Evans blue staining protocol for $P$. brassicae resting spores that improved uptake of the stain by nonviable spores. This modification greatly improved discrimination between viable and nonviable spores. Finally, the ability of the modified Evans blue method to measure nonviable $P$. brassicae resting spores was compared with canola root infection bioassays and the PMA qPCR method.

\section{Materials and Methods}

Evans blue staining of $\boldsymbol{P}$. brassicae resting spores. Isolation of P. brassicae resting spores. Symptomatic canola roots were obtained from 12-week-old plants growing in a naturally infested field near Brooks, Alberta. The roots were washed, and intact clubroot galls were collected and stored at $-20^{\circ} \mathrm{C}$ until further processing. Resting spores were obtained by thawing frozen galls overnight at room temperature and then, placing them in an air dryer set at $20^{\circ} \mathrm{C}$ for 7 days. Dried galls were ground into a coarse powder with a model 4 Thomas-Wiley laboratory mill (Arthur H. Thomas Company) using a 2-mil coarse screen. Three grams of ground gall material was suspended in $25 \mathrm{ml}$ of $5 \%$ glycerol solution prepared in distilled water. The suspension was agitated for 5 to $10 \mathrm{~min}$ at room temperature and then, filtered through eight layers of cheesecloth. The resulting spore suspension was mixed thoroughly for $5 \mathrm{~min}$ at room temperature with a magnetic stirrer. Resting spore suspensions $>4$ h old were discarded and not used. Final concentrations of resting spore suspensions were between $1.0 \times 10^{8}$ and $2.2 \times 10^{8}$ spores per milliliter ${ }^{-1}$.

Heat treatment. Five-milliliter aliquots of spore suspension were placed into 8 -ml $(13 \times 100-\mathrm{mm})$ glass tubes, capped, and incubated in a AccuBlock model D1100 digital dry bath heat block (Labnet International Inc.) that was preheated and held at the predefined experimental temperature. After exposure, tubes were removed from the heat block and kept at room temperature. Five replicate tubes were exposed at each temperature and time, including a nonheated (room temperature) control.

To determine the effect of staining time on uptake of Evans blue stain by $P$. brassicae resting spores, a sample of resting spores was treated at $80^{\circ} \mathrm{C}$ for $72 \mathrm{~h}$. Resting spores were evaluated every $30 \mathrm{~min}$ for the first $2 \mathrm{~h}$; hourly up to $12 \mathrm{~h}$; and then, at 24, 48, and $72 \mathrm{~h}$. A nonheated (0-h) sample was also evaluated.

Evans blue staining. Immediately after heat treatment, spore suspensions were gently mixed, and $50 \mu \mathrm{l}$ were transferred to a $1.5-\mathrm{ml}$ microcentrifuge tube containing an equal volume of freshly prepared Evans blue stain solution (Sigma-Aldrich) prepared at $20 \mathrm{mg} \mathrm{ml}^{-1}$. The staining solution was incubated uncovered at room temperature for the prescribed exposure time. Resting spore staining was visualized using bright-field microscopy with a Zeiss Axio imager M2 microscope (Carl Ziess) at 1,000× magnification. A total of 100 spores per sample were evaluated for each of five replicates, and the number of spores having cytoplasm stained dark blue was recorded. The percentage of viable spores was calculated for each. All experiments described herein used an "overnight" stain exposure time of 18 to $20 \mathrm{~h}$, with the exception of the time course staining experiment that compared multiple staining exposure times.

Clubroot bioassays. There were 14 canola seedlings per treatment replicated five times using the clubroot-susceptible cultivar $45 \mathrm{H} 31$ (DuPont Pioneer). After the heat treatment, $5 \mathrm{ml}$ of treated resting spore suspension was poured into a disposable $35-\mathrm{mm}$ petri dish, and the roots of each canola seedling were swished in the spore suspension for $\sim 10 \mathrm{~s}$ and then, transplanted into a prepared Cone-tainer root trainer (Stuewe and Sons Inc.) containing $\sim 55 \mathrm{~g}$ of premoistened Sunshine Mix \#4 medium (Sun Gro Horticulture). After transplanting, the seedling base was inoculated by pipetting $200 \mu \mathrm{l}$ of spore suspension from the second tube into a small depression on the media surface. The $P$. brassicae resting spore concentration in each sample was $\sim 1.0 \times 10^{8}$ spores per milliter ${ }^{-1}$. Based on the volume of spore suspension used in the bioassay, each Cone-tainer would have contained $\sim 3.6 \times 10^{5}$ spores per gram $^{-1}$ of growth medium. All cones were placed into a Cone-tainer tray and incubated in a GC-20 growth chamber (BioChambers) at ambient humidity and a light/dark cycle of $16 \mathrm{~h}$ at $23^{\circ} \mathrm{C}$ with maximum light intensity and $8 \mathrm{~h}$ at $18^{\circ} \mathrm{C}$ with no light. Each treatment was placed in a separate tray to prevent any cross-contamination. Plants were gently hand watered five times each week to saturation with tap water and fertigated 2 days each week to saturation with a prepared nutrient solution $(\mathrm{N}=225 \mathrm{ppm}$; $\mathrm{P}=61 \mathrm{ppm} ; \mathrm{K}=302$ ppm; $\mathrm{Ca}=190$ ppm; and pH 6.0).

Canola plants were grown under these conditions for 6 weeks, after which their roots were gently removed from the Cone-tainers, carefully rinsed with tap water, and then, visually rated for clubroot symptoms. Disease incidence was calculated as the percentage of plants with symptoms of clubroot. Disease severity was estimated using a visual rating scale ranging from 0 to 3 as follows: 0 (no disease), 1 (small galls on less than one-third of the roots), 2 (small to medium galls on one-third to two-thirds of roots), and 3 (medium to large galls on more than two-thirds of roots) (Kuginuki et al. 1999). The index of disease was calculated as described by Strelkov et al. (2018):

$$
\frac{=\sum(n \times 0+n \times 1+n \times 2+n \times 3)}{N \times 3} \times 100
$$

where $n$ is the number of plants in a class; $N$ is the total number of plants; and $0,1,2$, and 3 are the symptom severity classes.

PMA treatment and qPCR detection of viable $P$. brassicae resting spores. PMA treatment. Resting spore suspensions containing $2.2 \times 10^{8}$ spores per milliliter ${ }^{-1}$ were treated at 70,80 , and $90^{\circ} \mathrm{C}$ for 0 to $5 \mathrm{~h}$. Samples were collected at each exposure time, and paired samples were evaluated using Evans blue staining or PMA qPCR. One hundred microliters of heat-treated resting spore suspensions were treated with PMA by adding $5 \mu$ PMA at a concentration of $1 \mathrm{mM}$ (final concentration $=47.62 \mu \mathrm{M}$ ). The tubes were shaken at $300 \mathrm{rpm}$ in the dark at room temperature for $30 \mathrm{~min}$, and then, they were set on ice and treated with a 500-W halogen light for $15 \mathrm{~min}$ at $20 \mathrm{~cm}$ above the sample. DNA was immediately extracted from each sample, and qPCR was performed.

DNA extraction and qPCR. All DNA extraction was performed using the Qiagen DNeasy PowerSoil Kit (Qiagen Canada). All extracted DNA was dissolved in $50 \mu 1$ water. A qPCR primer set specific to the ribosomal DNA region of $P$. brassicae, CRqF2 (CTAGCGCTG CATCCCATATC) and CRqR2 (TGTTTCGGCTAGGATGGTTC), and the probe PB1 (56-FAM/CCATGTGAA/ZEN/CCGGTGAC/ 3IABkFQ) were manually designed according to the GenBank accession number KX011135. Using this primer set, qPCR analysis was conducted in a BioRad SsoAdvanced Univ Probe qPCR master mix with a CFX Connect cycler (Bio-Rad Canada). The qPCR programs and cycling parameters were 1 cycle at $95^{\circ} \mathrm{C}$ for 2 min followed by 40 cycles at $95^{\circ} \mathrm{C}$ for $5 \mathrm{~s}$ and $60^{\circ} \mathrm{C}$ for $30 \mathrm{~s}$. All DNA samples in all qPCR analyses were prepared as three technical repeats, where all components of the qPCR reactions mixtures were identical and contained $2 \mu l$ of DNA template. A primer efficiency standard curve analysis was done using resting spores of a field population of $P$. brassicae prepared as three $100-\mu l$ suspensions, each containing $4 \times 10^{7}$ spores. DNA was extracted from these three samples, and each of the resultant DNAs was serially diluted six times by 10 -fold each. qPCR analysis was performed on these samples, and a standard curve was generated. Based on the equation of the primer efficiency, spore number in the original DNA sample could be calculated from the qPCR cycle threshold (CT) value (Fig. 1). To determine the efficiency of the PMA qPCR, a resting spore suspension was prepared from the field population at a concentration of $1.5 \times 10^{8}$ spores per milliliter ${ }^{-1}$. An aliquot of this suspension was treated at $95^{\circ} \mathrm{C}$ for $10 \mathrm{~min}$. After cooling to room temperature, aliquots of this suspension were mixed with untreated viable spores in different ratios to create serial dilutions containing 0,20 , $40,60,80$, or $100 \%$ of living spores. These suspensions were prepared 
in $100 \mu \mathrm{l}$ final volumes and thus, consisted of $1.5 \times 10^{7}$ spores per tube. Three sets of such serial suspensions were prepared to make up three biological repeats.

Statistical analyses. Statistical analyses were performed using Minitab (Minitab Inc.). A mixed model analysis of variance (ANOVA) was performed using general linear model (GLM) to determine significant differences for main factors and interactions between factors. Subsequently, Tukey's multiple comparisons tests were performed to determine statistically significant separations of means within each main factor.

Regression analyses were performed for both Evans blue and PMA qPCR using results at each heat exposure time point. Bonett and Levene tests were performed to determine if the ratios of the pairwise regression results varied significantly from one. Where the ratios did not differ significantly from one, they were used to perform a Demmings (orthogonal) regression to determine the equivalency of the methods.

Secondary experimental repeats were conducted to confirm consistency. Similar results were obtained in all repeats, but data from multiple experiments were not pooled for statistical analyses.

\section{Results}

Evans blue staining of $\boldsymbol{P}$. brassicae resting spores. Heated samples showed a consistent increase in stain uptake for $\sim 8 \mathrm{~h}$, after which no additional increase in staining was seen for up to $72 \mathrm{~h}$ (Fig. 2). The percentage of staining of heat-treated resting spores increased with exposure time up to a maximum of $82 \%$ by $8 \mathrm{~h}$ and then, did not change significantly from 9 to $72 \mathrm{~h}$. The model had an $R^{2}=96.88$; ANOVA showed that time was a significant factor $(P<0.001)$, but replicate was not $(P=0.137)$, and that the final mean percentage of staining became exclusive after $7 \mathrm{~h}$ (Table 1). The heat treatment

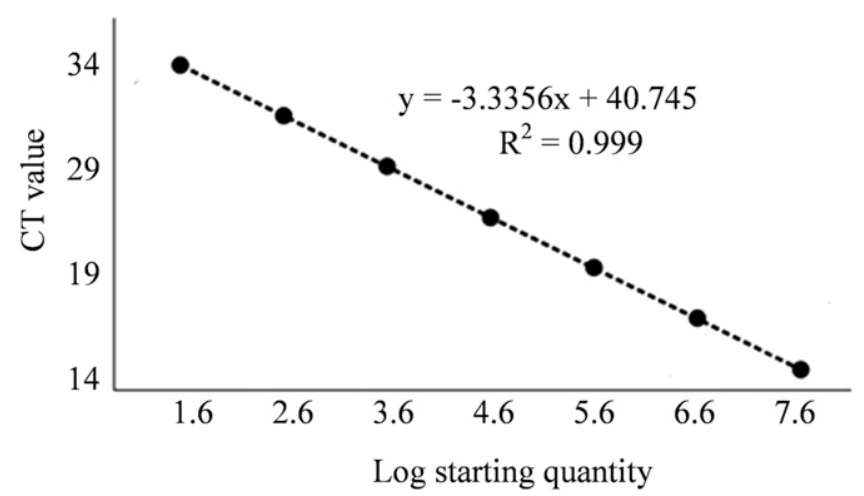

Fig. 1. Standard curve of the primer set used for Plasmodiophora brassicae quantitative PCR. CT = cycle threshold.

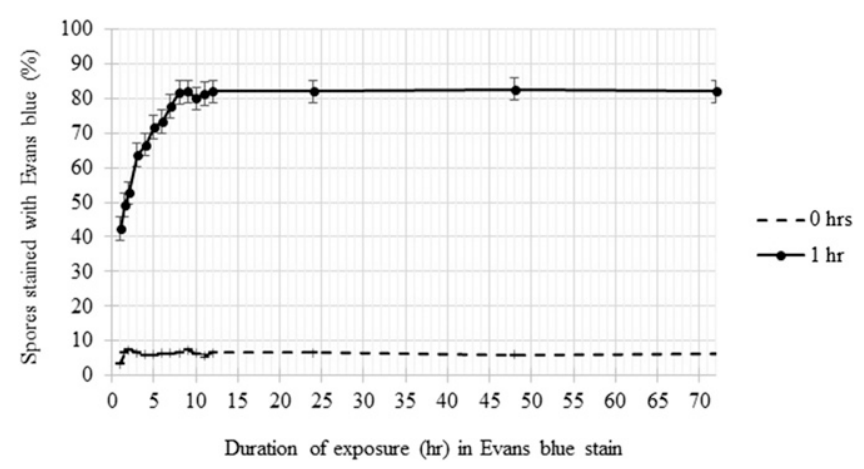

Fig. 2. Percentage of spores stained with Evans blue with increasing duration of staining. The solid line shows staining results for resting spores that had been heat treated $\left(80^{\circ} \mathrm{C}\right.$ for $\left.1 \mathrm{~h}\right)$. The dashed line shows staining results for nonheated spores. Error bars represent the standard error of the mean. Statistically significant differences between sample means are given in Table 1 . led to a higher percentage of staining compared with the untreated sample, presumably because of heat-induced inactivation or killing of resting spores. The nonheated sample reached a maximum of $6.7 \%$ stained at $2 \mathrm{~h}$ and remained more or less constant for the remainder of the trial (Fig. 2). Exposures of $>7 \mathrm{~h}$ to Evans blue stain were sufficient for differential staining of viable and nonviable spores (Fig. 3).

Resting spore staining was compared with viability in a canola infection bioassay using a paired sample. Treatments at 100 and $80^{\circ} \mathrm{C}$ caused the viable (nonstained) spore concentration to drop below $50 \times 10^{7}$ after the first exposure times of 0.5 and $1 \mathrm{~h}$, respectively, which was sufficient to reduce the disease index to zero or near zero. At 90,70 , and $60^{\circ} \mathrm{C}$, the numbers of viable spores declined more gradually. The numbers of viable spores and the disease indexes followed similar trends until the viable spores dropped below a threshold necessary for infection (between 35 and $75 \times 10^{7}$ ), after which the

Table 1. Separations of means for percentage resting spores staining with Evans blue for 17 exposure times using Tukey's pairwise comparisons; means that do not share a common letter are significantly different at $P<0.001$

\begin{tabular}{lc}
\hline Exposure (h) & Spores stained (\%) \\
\hline 0.5 & $28.3 \mathrm{f}$ \\
1 & $42.3 \mathrm{e}$ \\
1.5 & $49.3 \mathrm{e}$ \\
2 & $52.7 \mathrm{de}$ \\
3 & $63.7 \mathrm{~cd}$ \\
4 & $66.7 \mathrm{bc}$ \\
5 & $71.7 \mathrm{abc}$ \\
6 & $73.3 \mathrm{abc}$ \\
7 & $77.7 \mathrm{ab}$ \\
8 & $80.0 \mathrm{a}$ \\
9 & $81.3 \mathrm{a}$ \\
10 & $81.7 \mathrm{a}$ \\
11 & $82.0 \mathrm{a}$ \\
12 & $82.0 \mathrm{a}$ \\
24 & $82.0 \mathrm{a}$ \\
48 & $82.0 \mathrm{a}$ \\
72 & $82.7 \mathrm{a}$ \\
\hline
\end{tabular}

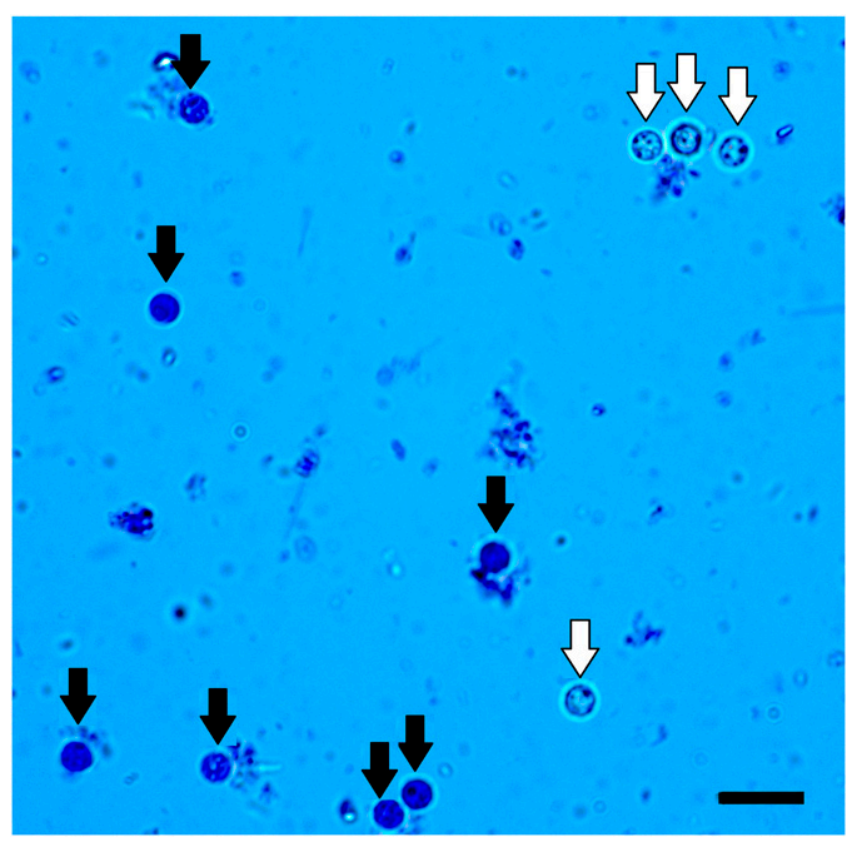

Fig. 3. Micrograph (1,000 $\times$ magnification) showing clubroot resting spores that have been heat treated at $80^{\circ} \mathrm{C}$ for $1 \mathrm{~h}$ and stained with Evans blue for $18 \mathrm{~h}$. Stained spores display dark blue cytoplasm (black arrows), and nonstained spores do not have blue stain inside the spores (white arrows). Bar $=10 \mu \mathrm{m}$. 
disease index dropped to zero or near zero. The $50^{\circ} \mathrm{C}$ treatment did not reduce viable resting spore concentrations to $<60 \times 10^{7}$, even after $48 \mathrm{~h}$ of exposure. As a result, although the disease index and resting spore viability dropped with increasing exposure times, the viable spores never dropped below the threshold for disease (Fig. 4). ANOVA indicated that there were statistically significant differences between exposure times $\left(R^{2}=99.47 ; P \leq 0.001\right)$ but not between replicates $(P=0.874)$. Tukey's pairwise comparisons revealed those means that were significantly different (Table 2).

PMA treatment and qPCR detection of viable $P$. brassicae resting spores. Evans blue measurements of resting spore mortality were compared with those of PMA qPCR measurements. The percentage of nonviable spores was accurately detected using PMA qPCR (Fig. 5). To compare the standard errors inherent in each
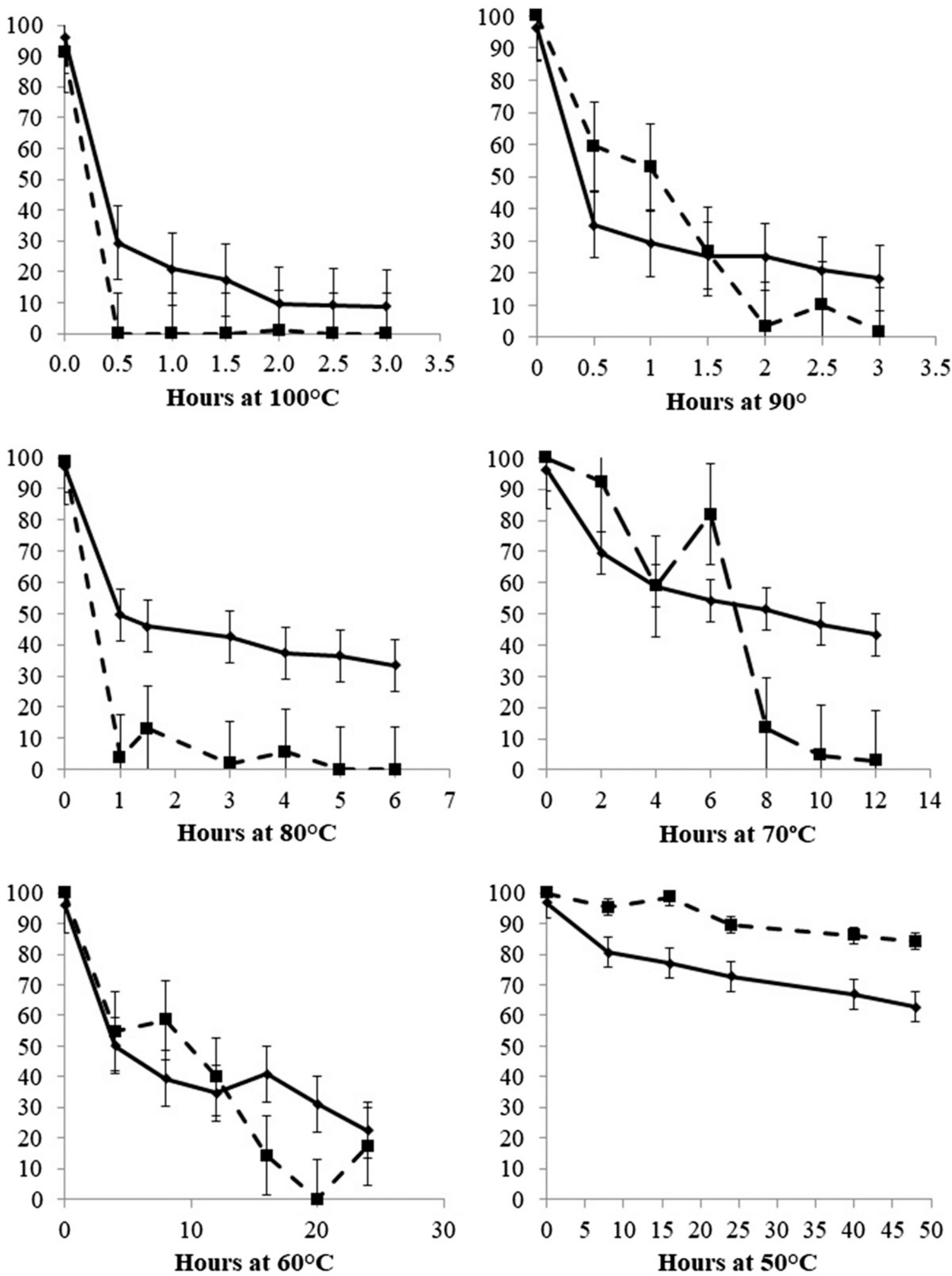

Fig. 4. Plasmodiophora brassicae resting spores exposed to $100,90,80,70,60$, and $50^{\circ} \mathrm{C}$ were divided into paired samples. Viable resting spore numbers $\left(\times 10^{7}\right)$ as measured by Evans blue staining are shown as solid lines. The dashed lines show clubroot disease index (percentage) values obtained from paired samples used in canola root infection bioassays. Error bars represent the standard error of the mean. Statistically significant differences between sample means are given in Table 2 . 
method, results for the $80^{\circ} \mathrm{C}$ experiment were plotted on a line graph showing the mean and the standard error above and below the mean. The standard error was greatest when Evans blue staining was performed for $30 \mathrm{~min}$, but it was greatly reduced when using the PMA qPCR and Evans blue 20-h staining methods (Fig. 6). A direct comparison of Evans blue 20-h staining and PMA qPCR revealed that the two methods had nearly identical killing curves at $90^{\circ} \mathrm{C}$, and at $80^{\circ} \mathrm{C}$, the curves for both methods were very similar (Fig. 7). However, at $70^{\circ} \mathrm{C}$, the PMA qPCR method seemed to underestimate the resting spore mortality at two of the time points compared with the Evans blue method (Fig. 7). ANOVA using GLM showed that, for both methods at all three temperature treatments, there were statistically significant differences between exposure times $\left(R^{2}=\right.$ 99.84; $P \leq 0.001)$ but no significant differences between replicates

Table 2. Separations of means for the numbers of viable resting spores and clubroot disease indexes at $100,90,80,70,60$, and $50^{\circ} \mathrm{C}$ using Tukey's pairwise comparisons; means within each column at the specified temperature that do not share a common letter are significantly different at $P \leq 0.001$

\begin{tabular}{|c|c|c|}
\hline $\begin{array}{l}\text { Exposure (h) at } \\
\text { different temperatures }\end{array}$ & $\begin{array}{l}\text { Viable resting } \\
\text { spores }\left(1^{7}\right)\end{array}$ & Disease index $(\%)$ \\
\hline \multicolumn{3}{|l|}{$100^{\circ} \mathrm{C}$} \\
\hline 0.0 & 95.9 a & $91.1 \mathrm{a}$ \\
\hline 0.5 & $29.4 \mathrm{~b}$ & $0.0 \mathrm{~b}$ \\
\hline 1.0 & $20.8 \mathrm{c}$ & $0.0 \mathrm{~b}$ \\
\hline 1.5 & $17.4 \mathrm{c}$ & $0.0 \mathrm{~b}$ \\
\hline 2.0 & $9.6 \mathrm{~d}$ & $1.0 \mathrm{~b}$ \\
\hline 2.5 & $9.1 \mathrm{~d}$ & $0.0 \mathrm{~b}$ \\
\hline 3.0 & $8.8 \mathrm{~d}$ & $0.0 \mathrm{~b}$ \\
\hline \multicolumn{3}{|l|}{$90^{\circ} \mathrm{C}$} \\
\hline 0.0 & $96.3 \mathrm{a}$ & $100.0 \mathrm{a}$ \\
\hline 0.5 & $34.9 \mathrm{~b}$ & $59.5 \mathrm{ab}$ \\
\hline 1.0 & $29.4 \mathrm{c}$ & $52.9 \mathrm{ab}$ \\
\hline 1.5 & $25.4 \mathrm{c}$ & $26.7 \mathrm{~b}$ \\
\hline 2.0 & $25.1 \mathrm{~cd}$ & $3.6 \mathrm{~b}$ \\
\hline 2.5 & $20.9 \mathrm{~d}$ & $10.0 \mathrm{~b}$ \\
\hline 3.0 & $18.4 \mathrm{~d}$ & $1.8 \mathrm{~b}$ \\
\hline \multicolumn{3}{|l|}{$80^{\circ} \mathrm{C}$} \\
\hline 0.0 & $97.1 \mathrm{a}$ & $98.6 \mathrm{a}$ \\
\hline 1.0 & $49.5 \mathrm{~b}$ & $3.8 \mathrm{~b}$ \\
\hline 1.5 & $45.9 \mathrm{bc}$ & $13.0 \mathrm{~b}$ \\
\hline 3.0 & $42.7 \mathrm{~cd}$ & $1.9 \mathrm{~b}$ \\
\hline 4.0 & $37.4 \mathrm{de}$ & $5.7 \mathrm{~b}$ \\
\hline 5.0 & $36.4 \mathrm{e}$ & $0.0 \mathrm{~b}$ \\
\hline 6.0 & $33.5 \mathrm{e}$ & $0.0 \mathrm{~b}$ \\
\hline \multicolumn{3}{|l|}{$70^{\circ} \mathrm{C}$} \\
\hline 0 & $96.5 \mathrm{a}$ & $100.0 \mathrm{a}$ \\
\hline 2 & $69.7 \mathrm{~b}$ & $92.4 \mathrm{a}$ \\
\hline 4 & $59.1 \mathrm{c}$ & $59.1 \mathrm{~b}$ \\
\hline 6 & $54.4 \mathrm{~d}$ & $81.9 \mathrm{ab}$ \\
\hline 8 & $51.6 \mathrm{~d}$ & $13.3 \mathrm{c}$ \\
\hline 10 & $46.8 \mathrm{e}$ & $4.8 \mathrm{c}$ \\
\hline 12 & $43.4 \mathrm{e}$ & $2.9 \mathrm{c}$ \\
\hline \multicolumn{3}{|l|}{$60^{\circ} \mathrm{C}$} \\
\hline 0 & $96.2 \mathrm{a}$ & $100.0 \mathrm{a}$ \\
\hline 4 & $50.1 \mathrm{~b}$ & $54.8 \mathrm{bc}$ \\
\hline 8 & $39.3 \mathrm{c}$ & $58.6 \mathrm{ab}$ \\
\hline 12 & $34.7 \mathrm{~cd}$ & $40.0 \mathrm{bcd}$ \\
\hline 16 & $41.0 \mathrm{c}$ & $14.3 \mathrm{~cd}$ \\
\hline 20 & $31.1 \mathrm{~d}$ & $0.0 \mathrm{~d}$ \\
\hline 24 & $22.4 \mathrm{e}$ & $17.2 \mathrm{bcd}$ \\
\hline \multicolumn{3}{|l|}{$50^{\circ} \mathrm{C}$} \\
\hline 0 & $96.8 \mathrm{a}$ & $100.0 \mathrm{a}$ \\
\hline 8 & $80.7 \mathrm{~b}$ & $95.2 \mathrm{a}$ \\
\hline 16 & $77.1 \mathrm{bc}$ & $98.6 \mathrm{a}$ \\
\hline 24 & $72.8 \mathrm{~cd}$ & $89.5 \mathrm{a}$ \\
\hline 40 & $67.0 \mathrm{de}$ & $86.2 \mathrm{a}$ \\
\hline 48 & $62.8 \mathrm{e}$ & $84.1 \mathrm{a}$ \\
\hline
\end{tabular}

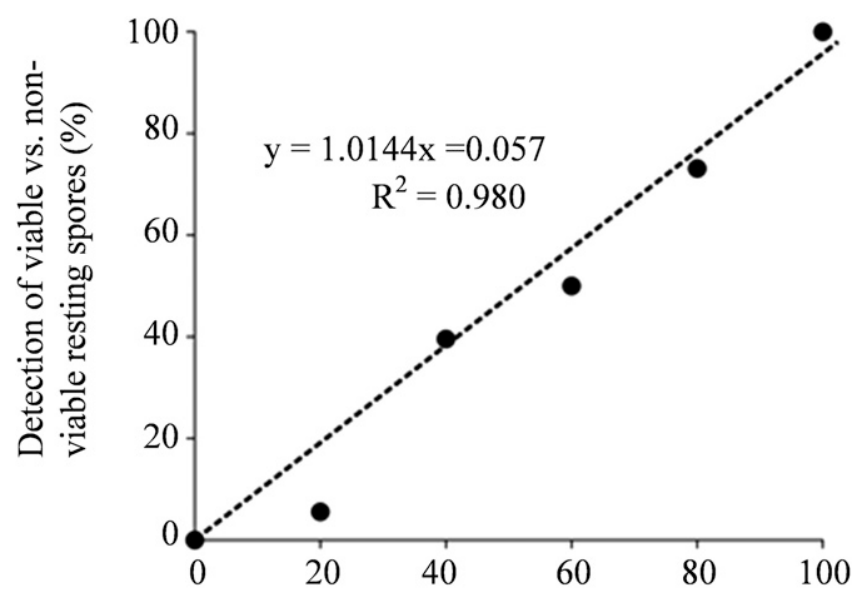

Heat-killed resting spores in sample (\%)

Fig. 5. Efficiency of living spore estimation by propidium monoazide quantitative PCR calculated using known ratios of heat-killed spores to viable resting spores.
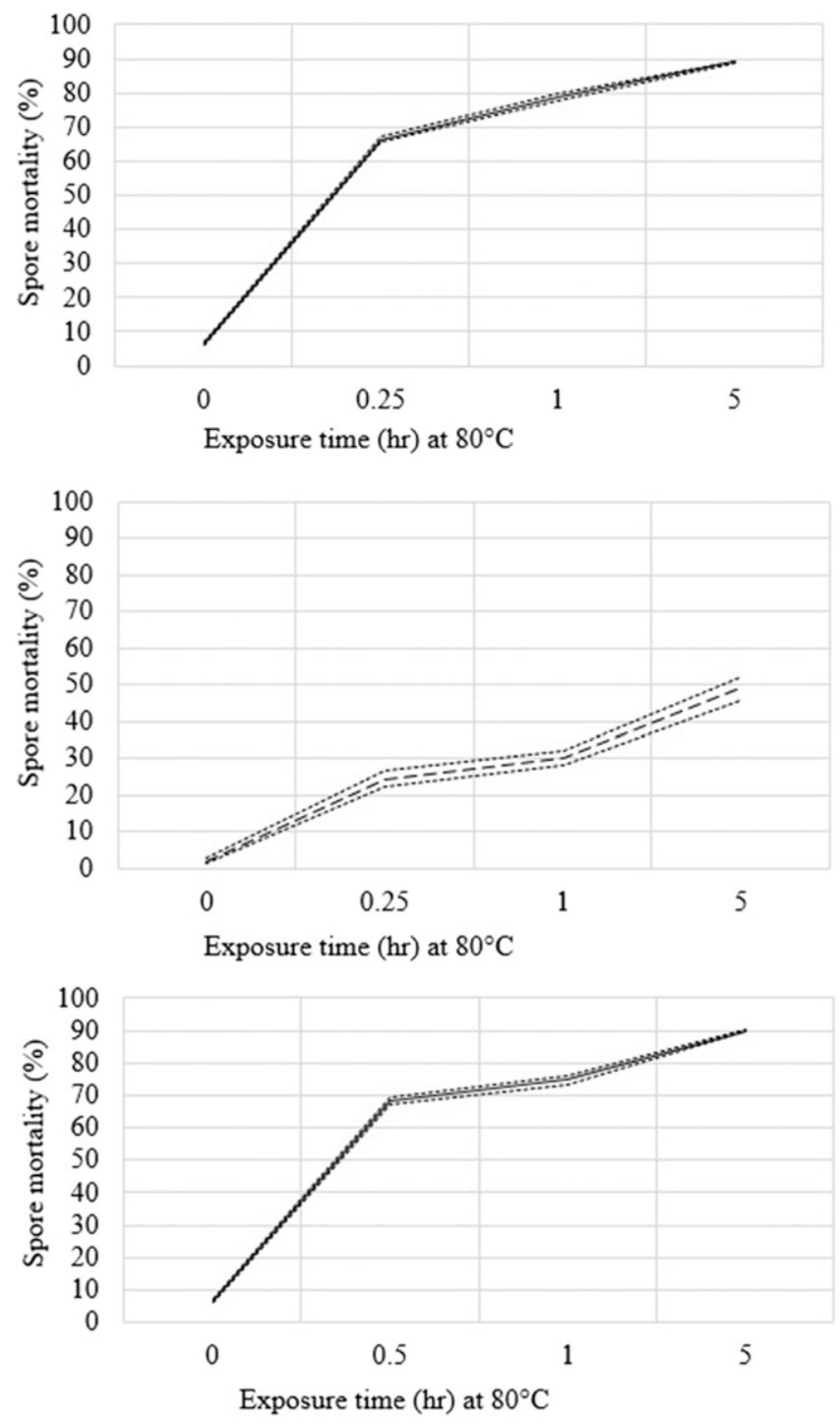

Fig. 6. Clubroot resting spore mortality after exposures at $80^{\circ} \mathrm{C}$. The dashed lines above the mean represents the mean plus the standard error, and the dashed lines below represents the mean minus the standard error. The top panel shows results for $18 \mathrm{~h}$ of staining with Evans blue, whereas the middle panel shows $30 \mathrm{~min}$ of staining with Evans blue, and the bottom panel shows results with propidium monoazide quantitative PCR. 
$(P=0.412)$. Finally, Tukey's pairwise comparisons for Evans blue 18-h staining resulted in a statistical separation of means for nearly every time point at all three temperatures, whereas significant differences between means from the PMA qPCR tests were less evident (Table 3).
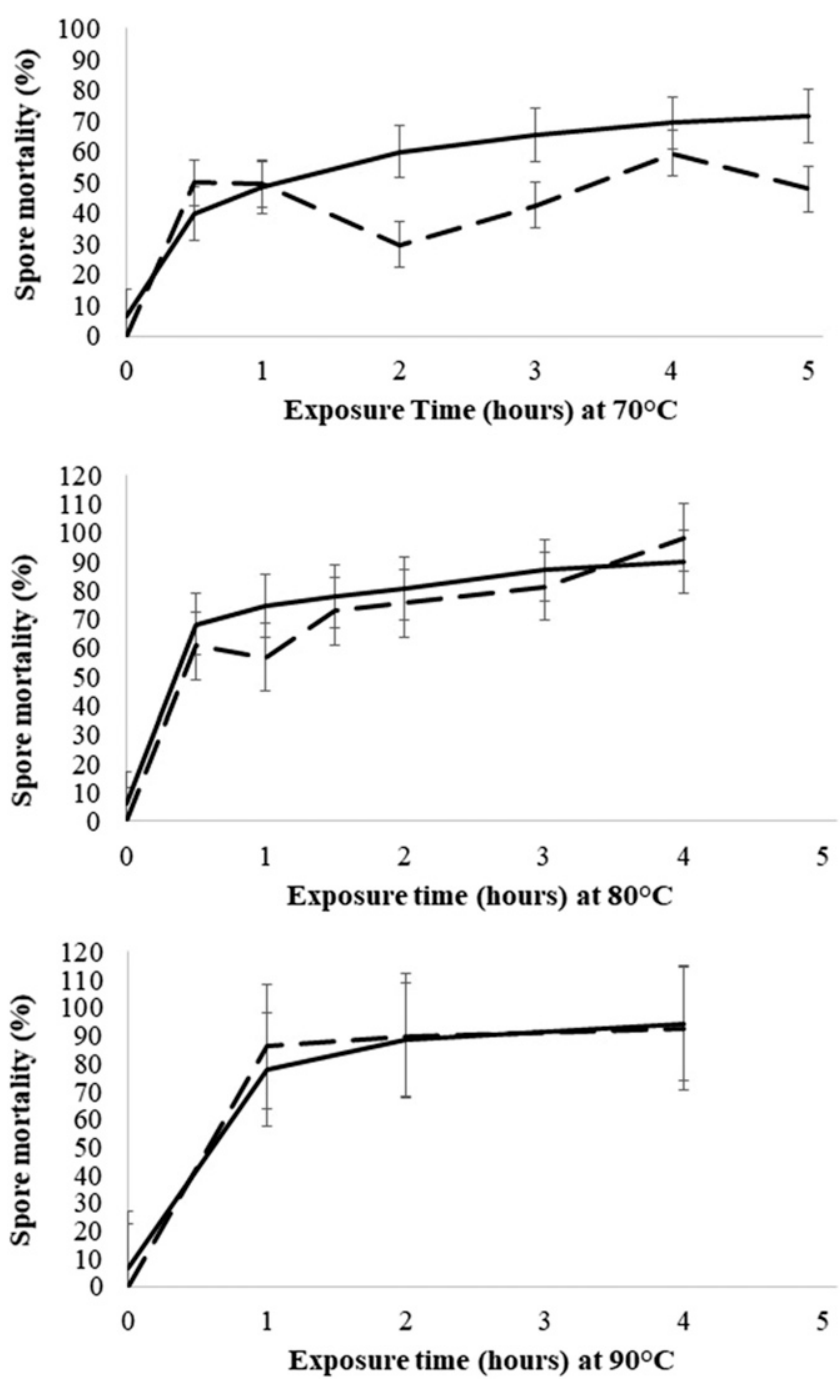

Fig. 7. Clubroot resting spore mortality after exposures to 90,80 , and $70^{\circ} \mathrm{C}$ as measured by Evans blue staining (solid lines) or propidium monoazide quantitative PCR (dashed lines). Error bars represent the standard error of the mean. Statistically significant differences between sample means are given in Table 2.

Table 3. Separations of means for percentage resting spore mortality for each exposure time at 70,80 , and $90^{\circ} \mathrm{C}$ using Tukey's pairwise comparisons; means within each column that do not share a common letter are significantly different at $P \leq 0.001$

\begin{tabular}{|c|c|c|c|c|c|c|}
\hline \multirow[b]{2}{*}{$\begin{array}{l}\text { Exposure } \\
\text { (h) }\end{array}$} & \multicolumn{2}{|c|}{$7^{\circ}{ }^{\circ} \mathrm{C}$} & \multicolumn{2}{|c|}{$80^{\circ} \mathrm{C}$} & \multicolumn{2}{|c|}{$90^{\circ} \mathrm{C}$} \\
\hline & $\begin{array}{c}\text { Evans } \\
\text { blue }\end{array}$ & $\begin{array}{c}\text { PMA } \\
\text { qPCR }^{\mathbf{P}}\end{array}$ & $\begin{array}{l}\text { Evans } \\
\text { blue }\end{array}$ & $\begin{array}{l}\text { PMA } \\
\text { qPCR }\end{array}$ & $\begin{array}{c}\text { Evans } \\
\text { blue }\end{array}$ & $\begin{array}{l}\text { PMA } \\
\text { qPCR }\end{array}$ \\
\hline 0 & $6.5 \mathrm{a}$ & $0.0 \mathrm{a}$ & $6.5 \mathrm{a}$ & $0.0 \mathrm{a}$ & $6.5 \mathrm{a}$ & $0.0 \mathrm{a}$ \\
\hline 0.5 & $40.0 \mathrm{~b}$ & $50.0 \mathrm{~b}$ & $68.3 \mathrm{~b}$ & $60.7 \mathrm{~b}$ & - & - \\
\hline 1 & $48.5 \mathrm{c}$ & $49.3 \mathrm{~b}$ & $74.8 \mathrm{c}$ & $56.8 \mathrm{~b}$ & $78.0 \mathrm{~b}$ & $86.1 \mathrm{~b}$ \\
\hline 1.5 & $-{ }^{\mathrm{z}}$ & - & $78.0 \mathrm{~cd}$ & $72.9 \mathrm{bc}$ & - & - \\
\hline 2 & $60.0 \mathrm{~d}$ & $29.8 \mathrm{~b}$ & $80.8 \mathrm{~d}$ & $75.5 \mathrm{bc}$ & $88.5 \mathrm{c}$ & $89.8 \mathrm{~b}$ \\
\hline 3 & $65.3 \mathrm{e}$ & $42.5 \mathrm{~b}$ & $87.0 \mathrm{e}$ & $81.3 \mathrm{~cd}$ & - & - \\
\hline 4 & $69.3 \mathrm{ef}$ & $59.5 \mathrm{~b}$ & $90.0 \mathrm{e}$ & $98.2 \mathrm{~d}$ & $94.3 \mathrm{~d}$ & $92.7 \mathrm{~b}$ \\
\hline 5 & $71.8 \mathrm{f}$ & $47.8 \mathrm{~b}$ & - & - & - & - \\
\hline
\end{tabular}

y PMA, propidium monoazide; qPCR, quantitative PCR.

${ }^{\mathrm{z}}$ Time point not evaluated at that temperature.
The statistical equivalence of the Evans blue and PMA qPCR methods was assessed using regression analyses. A separate regression analysis was performed for each of the three temperatures. A ratio of variance (Evans blue/qPCR) was calculated for each temperature. The ratios did not significantly differ from one according to both the Bonett and Levene tests (Table 4), indicating that the methods did not significantly vary. These ratios were then used to perform a Demmings (orthogonal) regression. Equivalent methods are defined as having 95\% confidence intervals that include zero for the slope and one for the intercept. The regressions showed that the two methods were equivalent for the $70^{\circ} \mathrm{C}$ heat treatment results and equivalent (or nearly equivalent) for the $90^{\circ} \mathrm{C}$ heat treatment results (Table 4). At $90^{\circ} \mathrm{C}$, the confidence interval for the intercept may have failed to include one; however, the upper end of the interval was 0.99 and essentially equal to one. Although this result indicated that the variance was constant but not proportional, the fact that the interval was $<1 / 100$ th from including one places this result on the very edge of variance. Results from the $80^{\circ} \mathrm{C}$ exposures showed that the confidence interval for slope failed to include zero, indicating that the methods were not equivalent and that the variance was proportional but not constant. Taken together, these results show little variance between the two methods and a high degree of equivalence between the Evans blue and PMA qPCR techniques for two of the three temperature treatments.

\section{Discussion}

Evans blue staining has been used for many years in plant and animal studies to distinguish between living and dead cells (Gaff and Okong'o-Ogola 1971; Gahan 1984). It was first used to evaluate $P$. brassicae resting spore viability by Takahashi and Yamaguchi (1987). Tanaka et al. (1999) also reported using Evans blue to evaluate $P$. brassicae spore viability based on a method used by Newcombe and Thomas (1990) to evaluate Ustilago nuda spore viability after fungicide treatments. These previous studies reported using staining times of 10 to $30 \mathrm{~min}$. Other experiments and published reports have indicated that Evans blue staining for 10 to 30 min cannot accurately distinguish between viable and nonviable spores (Al-Daoud et al. 2017) (Howard and Harding, unpublished data). The primary problem with the 10 - to 30 -min staining procedure was that many of the nonviable spores that should have appeared dark blue were unstained or partially stained, thereby underestimating the actual mortality. Partial or incomplete staining introduced a degree of uncertainty that, in the worst case, made it impossible to distinguish between viable and nonviable spores and in the best case, introduced experimental error because of the subjectivity of categorizing weakly stained or partially stained cells. The increase in standard error was easily seen between the 15-min staining and the 18-h staining (Fig. 6). Increasing the exposure time to the stain to $>8 \mathrm{~h}$ improved the ability to discriminate viable from nonviable spores, and the results were confirmed in the canola infection bioassay, where the index of disease dropped proportionally with the spore viability predicted by the staining (Fig. 4) and revealed that, for our bioassay conditions, the threshold for disease symptoms

Table 4. Evaluation of statistical equivalence of Evans blue staining results compared with those of propidium monoazide quantitative PCR (qPCR) using Demmings regression

\begin{tabular}{|c|c|c|c|}
\hline & $7^{\circ} \mathrm{C}$ & $80^{\circ} \mathrm{C}$ & $90^{\circ} \mathrm{C}$ \\
\hline $\begin{array}{l}\text { Ratio of variances (Evans blue/ } \\
\text { qPCR) }\end{array}$ & $1.021^{\mathrm{x}}$ & $0.799^{x}$ & $0.814^{\mathrm{x}}$ \\
\hline $95 \%$ Confidence interval for slope & $-7.02-29.72$ & $3.22-21.68^{\mathrm{y}}$ & $-0.88-13$ \\
\hline $\begin{array}{l}\text { 95\% Confidence interval for } \\
\text { intercept }\end{array}$ & $0.58-1.44$ & $0.76-1.03$ & $0.81-0.9$ \\
\hline
\end{tabular}

${ }^{\mathrm{x}}$ Not significantly different from one according to Bonnett and Levene tests.

${ }^{y}$ Interval fails to include zero; therefore, methods are not equivalent, and variance was proportional and not constant.

${ }^{\mathrm{z}}$ Interval fails to include one; therefore, methods are not equivalent, and variance was constant and not proportional. 
was between $30 \times 10^{7}$ and $75 \times 10^{7}$ resting spores or $\sim 1 \times 10^{5}$ to $2 \times$ $10^{5}$ spores per gram $^{-1}$ of growth media.

Improved fluorescent staining of Uromyces appendiculatus colonies within leaves of dry bean (Phaseolus vulgaris L) was achieved by lengthening the incubation times, sometimes up to $48 \mathrm{~h}$ (Harding et al. 2000). Additionally, others have used extended staining periods with Evans blue to more accurately measure cell death in planta (Dekhuijzen et al. 1978). We have demonstrated improvement in staining of dead $P$. brassicae resting spores with Evans blue because of extending the staining period from $30 \mathrm{~min}$ to $\geq 8 \mathrm{~h}$.

The accuracy of Evans blue staining to predict spore viability was also confirmed by PMA qPCR analyses (Fig. 7). Comparatively, the Evans blue method produced incremental curves without anomalies and consistently detected incremental changes in resting spore mortality directly related to increased exposure for all temperatures tested. The PMA qPCR method was also able to accurately detect reductions in spore viability, but the spore mortality curves were slightly erratic for the 70 and $80^{\circ} \mathrm{C}$ heat treatments. For example, when spores were exposed to $70^{\circ} \mathrm{C}$, the spore viability predicted by the PMA qPCR method fluctuated from $50 \%$ at 0.5 and $1 \mathrm{~h}$ to $30 \%$ before climbing again (Fig. 7). Despite these fluctuations, orthagonal regression confirmed that the Evans blue method and PMA qPCR were equivalent for two of the three heat treatment experiments. However, the statistical analyses revealed that Evans blue had a reduced variance and greater capacity to statistically separate incremental heat treatment exposures (Table 3).

It is reasonable to assume that spore mortality will increase incrementally with exposure time to high temperatures of 60 to $100^{\circ} \mathrm{C}$. This hypothesis was supported in all of the curves reported herein, except for the Evans blue method at $60^{\circ} \mathrm{C}$ (solid line in the bottom left panel of Fig. 4) and the PMA qPCR method at $70^{\circ} \mathrm{C}$ (dashed line in the top panel of Fig. 7). It is interesting to note that these departures from a predicted curve occurred only at the lowest-temperature experiments. One hypothesis to explain this observation is that perhaps the immediate severity of physical damage to spores decreases with lower-temperature treatments such that it becomes more difficult to detect nonviable spores. This hypothesis was also supported by the fact that nonheated spore suspensions reached maximum staining with a 3-h incubation but that heat-treated spores required $8 \mathrm{~h}$ of exposure to achieve complete staining (Fig. 2). In other words, a continuum of detectable mortality may exist within a population of resting spores such that some were easily detected as nonviable and some were clearly viable, but the remainder were not easy to discriminate. Treatments at high temperatures, such as $80^{\circ} \mathrm{C}$ and above, would likely cause more rapid, severe physical damage to spores, which allowed easy access of the Evans blue stain and the PMA, whereas at lower temperatures, the damage may have been less extreme, and consequently, spores' viabilities may have been more difficult to assess. This speculation may warrant additional testing of the PMA qPCR method to see if longer PMA incubation times can improve its activity in a manner similar to the results reported herein for Evans blue.

The improved Evans blue staining method for $P$. brassicae resting spores will be a valuable means of evaluating disease potential within populations of resting spores and effects of treatments intended to inactivate them. The improved method accurately estimates disease potential measured in a bioassay without the need for a living host or waiting 6 weeks for bioassay results, and it is as accurate as PMA qPCR. This procedure will be especially useful for evaluations of physical treatments and chemical disinfectants or fungicides used to inactivate resting spores as part of equipment sanitization protocols aimed at preventing the spread of $P$. brassicae.

\section{Acknowledgments}

The authors thank D. A. Burke, S. L. I. Lisowski, C. A. Pugh, and C. McConnell for their contributions.

\section{Literature Cited}

Al-Daoud, F., Gossen, B. D., Robson, J., and McDonald, M. R. 2017. Propidium monoazide improves quantification of resting spores of Plasmodiophora brassicae with qPCR. Plant Dis. 101:442-447.

Dekhuijzen, H. M., Bossen, M. E., and Vonk, C. R. 1978. The uptake of cytokinins by protoplasts and root sections of Brassica campestris. Physiol. Plant. 43:142-147.

Fayolle, L., Noble, R., Coventry, E., Aime, S., and Alabouvette, C. 2006. Eradication of Plasmodiophora brassicae during composting of wastes. Plant Pathol. 55:553-558.

Gaff, D. F., and Okong'o-Ogola, O. 1971. The use of non-permeating pigments for testing the survival of cells. J. Exp. Bot. 22:756-758.

Gahan, P. B. 1984. Plant Histochemistry and Cytochemistry. Academic Press, London, United Kingdom.

Gossen, B. D., Strelkov, S. E., Manolii, V. P., Rennie, D. C., Cao, T., Hwang, S. F., Peng, G., and McDonald, M. R. 2015. Spread of Plasmodiophora brassicae on canola in Canada, 2003-2014: Old pathogen, new home. Can. J. Plant Pathol. 37:403-413.

Harding, M. W., Stutz, J. C., and Roberson, R. W. 2000. Host-parasite relationships in bean cultivars of varying susceptibility to bean rust. Can. J Bot. 77:1551-1559.

Howard, R. J., Strelkov, S. E., and Harding, M. W. 2010. Clubroot of cruciferous crops - new perspectives on an old disease. Can. J. Plant Pathol. 32:43-57.

Hwang, S. F., Howard, R. J., Strelkov, S. E., Gossen, B. D., and Peng, G. 2014. Management of clubroot (Plasmodiophora brassicae) on canola (Brassica napus) in western Canada. Can. J. Plant Pathol. 36 (sup1):49-65.

Kageyama, K., and Asano, T. 2009. Life cycle of Plasmodiophora brassicae. J. Plant Growth Regul. 28:203-211.

Kuginuki, Y., Yoshikawa, H., and Hirai, M. 1999. Variation in virulence of Plasmodiophora brassicae in Japan tested with clubroot-resistant cultivars of Chinese cabbage (Brassica rapa L. ssp. pekinensis). Eur. J. Plant Pathol. 105:327-332.

Lahlali, R., and Peng, G. 2014. Suppression of clubroot by Clonostachys rosea via antibiosis and induced host resistance. Plant Pathol. 63:447-455.

Lahlali, R., Peng, G., McGregor, L., Gossen, B. D., Hwang, S. F., and McDonald, M. 2011. Mechanisms of the biofungicide Serenade (Bacillus subtilis QST713) in suppressing clubroot. Biocontrol Sci. Technol. 21:1351-1362.

Lee, M. L., and Hsieh, W. H. 1992. Influence of $\mathrm{pH}$, sodium and potassium salts on viability of resting spores of Plasmodiophora brassicae. Plant Pathol. Bull. 1: 31-36.

Myers, D. F., Campell, R. N., and Greathead, A. S. 1983. Thermal inactivation of Plasmodiophora brassicae Woron. and its attempted control by solarization in the Salinas Valley of California. Crop Prot. 2:325-333.

Newcombe, G., and Thomas, P. L. 1990. Fungicidal and fungistatic effects of carboxin on Ustilago nuda. Phytopathology 80:509-512.

Rennie, D. C., Manolii, V. P., Cao, T., Hwang, S. F., Howard, R. J., and Strelkov, S. E. 2011. Direct evidence of surface infestation of seeds and tubers by Plasmodiophora brassicae and quantification of spore loads. Plant Pathol. 60:811-819.

Strelkov, S. E., Hwang, S. F., Manolii, V. P., Cao, T., Fredua-Agyeman, R., Harding, M. W., Peng, G., Gossen, B. D., Mcdonald, M. R., and Feindel, D. 2018. Virulence and pathotype classification of Plasmodiophora brassicae populations collected from clubroot resistant canola (Brassica napus) in Canada. Can. J. Plant Pathol. 40:284-298.

Strelkov, S. E., Manolii, V. P., Harding, M. W., Hwang, S. F., Fei, W., Rong, S., Burke, D. A., Pugh, C. A., Nielsen, J. M., Barnes, A., and Jacobsen, C. 2015. The spread of clubroot on canola in Alberta in 2014. Can. Plant Dis. Surv. 95:155-158.

Strelkov, S. E., Manolii, V. P., Harding, M. W., Hwang, S. F., Poscente, N., Lisowski, S. L. I., Pugh, C. A., and Burke, D. A. 2014. The occurrence of clubroot on canola in Alberta in 2013. Can. Plant Dis. Surv. 94:158-161.

Takahashi, K., and Yamaguchi, T. 1987. An improved method for estimating the number of resting spores of Plasmodiophora brassicae in soil. Jpn. J. Phytopathol. 53:507-515.

Tanaka, S., Kochi, S. I., Kunita, H., Ito, S. I., and Kameya-Iwaki, M. 1999. Biological mode of action of the fungicide, flusulfamide, against Plasmodiophora brassicae (clubroot). Eur. J. Plant Pathol. 105:577-584.

Tewari, J. P., Strelkov, S. E., Orchard, D., Hartman, M., Lange, R. M., and Turkington, T. K. 2005. Identification of clubroot of crucifers on canola (Brassica napus) in Alberta. Can. J. Plant Pathol. 27:143-144.

Wichuk, K. M., Tewari, J. P., and McCartney, D. 2011. Plant pathogen eradication during composting: A literature review. Compost Sci. Util. 19:244-266. 